\title{
NINJA PROG - JOGO DE CONCEITOS MATEMÁTICOS E LÓGICA DE PROGRAMAÇÃO
}

\author{
Claudio Lima Rhenns, André Luis Alice Raabe, André Santana \\ Universidade do Vale do Itajaí - UNIVALI \\ Rua Uruguai 458 - Itajaí - SC - Brasil \\ rhennsfotos@yahoo.com.br, raabe@univali.br, andrelms@univali.br
}

\begin{abstract}
Resumo. Os cursos de Tecnologia da informação costumam apresentar taxas altas de evasão e reprovação. Dentre as disciplinas que pertencem às grades destes cursos, encontram-se as disciplinas introdutórias de lógica de programação de computadores. Com base em pesquisas realizadas nas grades curriculares da IEEE-CS, ACM e SBC, ficou entendido que o aluno ingresso já deva ter conhecimento de conceitos básicos de matemática e lógica ao iniciar estes cursos, mas na realidade isso não se comprova. Este documento traz informações sobre um jogo que foi desenvolvido para auxiliar no aprendizado de tais conceitos. É esperado que o jogo contribua no aprendizado desses conceitos tornando o processo de aprendizagem de programação introdutória um pouco mais simples, ajudando na assimilação da disciplina por parte dos alunos e proporcionando um possível despertar de interesse na disciplina por parte dos usuários em geral. O jogo não possui códigos ou scripts, é um jogo que busca trabalhar os conceitos da matemática preliminar e raciocínio lógico.
\end{abstract}

\section{Cenário de uso}

Independentemente da metodologia e dos paradigmas utilizados, lógica de programação é requisito fundamental nos cursos de computação, sendo instrumento importante na estruturação de raciocínio lógico e formulação de algoritmos corretos. No entanto, muitas vezes a condução desse estudo é visto com preocupação pelos alunos, sendo que mesmo antes do começo das atividades já se forma uma resistência perante o conteúdo, fato que pode ocorrer, segundo JARVINEN (2005), por sua característica lógico-matemática, dado o enraizado estigma relacionado a esse conteúdo.

Jenkins (2002) afirma que o grande proposito do ensino de programação é conseguir com que os alunos desenvolvam sistemas computacionais capazes de resolver problemas reais, porém é observado que uma taxa significativa de alunos enfrenta problemas ao ter de aplicar noções básicas de matemática e abstração na criação de algoritmos que resolvam os problemas propostos.

Este documento descreve de forma resumida o processo de criação e objetivo do jogo intitulado como "Ninja Prog". O jogo foi desenvolvido com o propósito de auxiliar no resgate ou ensino dos conceitos fundamentais de lógica e matemática necessários para a compreensão das disciplinas de lógica de programação. É esperado que o jogo 
auxilie no engajamento de novos estudantes dos cursos superiores ou técnicos que tenham relação com as disciplinas introdutórias de programação e torne um pouco mais claro o entendimento de alguns princípios fundamentais dessas disciplinas. O jogo é destinado portanto aos estudantes de ensono dos níveis médio ( cursos técnicos de programação por exemplo) e superior ( acadêmicos dos cursos que envolvam as disciplinas de programação introdutória, por exemplo).

\section{Desenvolvimento}

O jogo Ninja Prog foi programado e organizado na plataforma de desenvolvimento de jogos e aplicativos Unity 3D. A versão utilizada do software Unity foi a versão 4.6. No momento de desenvolvimento do jogo.

A linguagem de programação utilizada no desenvolvimento do jogo foi a linguagem de Javascript. Durante o desenvolvimento do projeto, foram criados 69 scripts. Os scripts estão ligados aos comportamentos dos personagens do jogo, do funcionamento dos menus e controles em geral.

O jogo Ninja Prog foi desenvolvido inicialmente para as plataformas de dispositivos móveis com Sistema operacional Android, na versão minima 2.3. É possível portanto jogar Ninja pro gem celulares e tablets. Os controles são realizados facilmente por meio de contatos na tela do dispositivo.

Inicialmente o jogo Ninja prog foi desenvolvido como um projeto de conclusão de Curso de Ciência da Compiutação da Universidade do Vale do Itajaí (UNIVALI). Como parte do processo de desenvolvimento foi realizada uma pesquisa afim de buscar descobrir algumas das razões de muitos novos estudantes enfrentarem grandes dificuldades ao iniciarem as disciplinas introdutórias de programação. Por meio de pesquisas e analises das grades curriculares dos cursos de tecnologia, foi percebido que é desejavel um nível básico de maturidade matemática ao se ingressarem nesses cursos.

O nível mínimo de maturidade matemática exigido pode variar entre diferentes cursos. Após analyses durante o processo de pesquisa, foram determinados então os conceitos que seriam trabalhados durante o jogo. Muitos jogos e ações, como a "hora do Código" foram observados com o intuito de inspirer a criação do jogo Ninja Prog assim como para determinar quais conceitos selecionados já eram abordados e quais não eram de forma satisfatória. 
V Congresso Brasileiro de Informática na Educação (CBIE 2016)

Anais dos Workshops do V Congresso Brasileiro de Informática na Educação (CBIE 2016)

\section{Apresentação do Software}

Para descrever o jogo "Ninja Prog", foi optado por se utilizar um modelo enxuto de game design, mais conhecido como "Game proposal". O vídeo de demonstração e explicação do jogo pode ser encontrado no link: https://youtu.be/btNM9O_z18A

\subsection{Conceito do Jogo}

O jogo Ninja prog busca exercitar, resgatar ou mesmo ajudar no entendimento dos conhecimentos básicos e fundamentais relativos a pensamento lógico e matemática necessários para a compreensão das disciplinas introdutórias de programação. O jogo propõe uma série de desafios matemáticos que exercitam o pensamento lógico.

\subsection{Mecânica do Jogo}

Dentro de cada fase o ninja precisa enfrentar alguns inimigos enquanto tenta validar as expressões matemáticas. Muitas vezes será necessário derrotar todos os inimigos antes de resolver o puzzle proposto pela fase. Em algumas fases não adianta ficar lutando, pois os inimigos só vão ser destruídos com a validação dos desvios condicionais.

Os primeiros desafios do jogo estão relacionados aos conceitos de manipulação de variáveis, contudo ao ir avançando nos níveis o jogador se depara com conceitos de laço de repetição, operações aritméticas e desvios condicionais.

Os enigmas são resolvidos na grande maioria arrastando caixas com valores de um lado para outro (figura 1), atribuindo essas caixas à portais, que representam variáveis e até realizando operações matemáticas com as caixas.

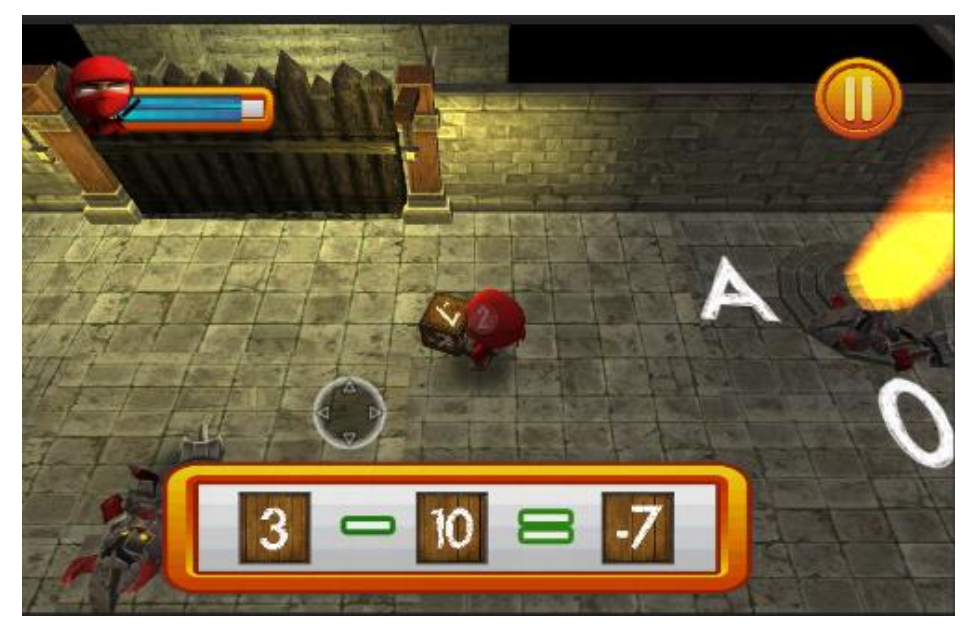

Figura 1. Exemplo de operações aritméticas realizadas no jogo 


\subsection{Enredo do jogo}

O personagem principal do jogo é um jovem programador. Este programador foi capturado e escondido em um calabouço a muitos metros abaixo do nível do mar. Quem o sequestrou, o grande vilão do jogo (Skelton), tem o intuito de obrigar o herói do jogo a desenvolver um programa que seja capaz de descobrir a senha da rede social (MonsterBook) de sua namorada. Muitos outros programadores já foram capturados e acabaram fracassando nas tentativas de fuga. O calabouço contém muitos andares, muitos níveis e em cada um existe um enigma (um problema) a ser desvendado. Cada programador que tentou fugir, foi mais longe e deixou para trás dicas de como vencer cada nível dessa fortaleza. Essas dicas foram escritas por eles mesmos no chão de cada nível. O espirito de um grande mestre da programação será o guia de nosso personagem nessa aventura, explicando muitas coisas necessárias para o progresso dentro do jogo.

\subsection{Personagens}

A seguir é realizada uma breve descrição dos personagens principais do jogo.

\section{Programador Ninja}

Na verdade ele nunca foi um ninja, não daqueles que lutam contra outros guerreiros com uma espada. O programador estava em uma festa a fantasia quando foi sequestrado. $\mathrm{O}$ fato de termos um ninja como protagonista, nos remete ao pensamento de alguém com habilidades especiais e é justamente essa visão que o jogo tenta passar, a visão de que os programadores tem habilidades especiais, que a programação poderia ser considerada como um poder especial. No nosso jogo o personagem vai adquirindo essas habilidades e são todas habilidades que vão ajuda-lo a resolver os problemas apresentados ( figura 2 )

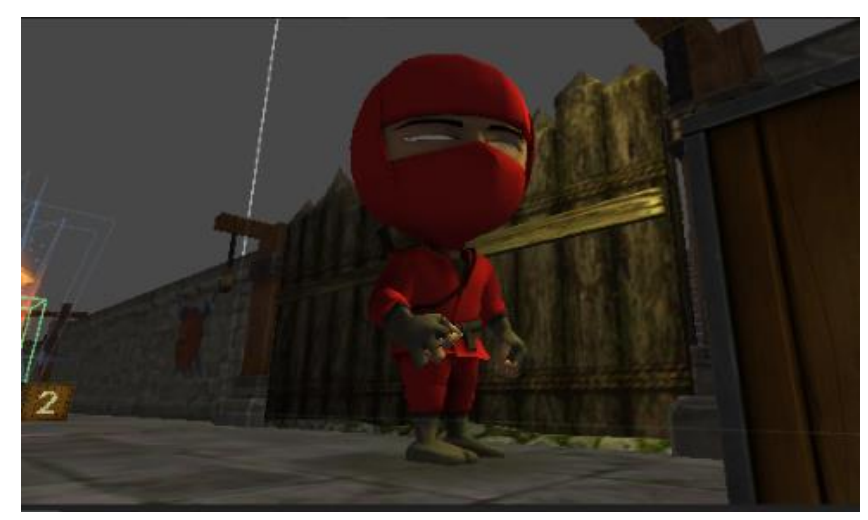

Figura 2. Programador Ninja

\section{O MESTRE PROGRAMADOR}


V Congresso Brasileiro de Informática na Educação (CBIE 2016)

Anais dos Workshops do V Congresso Brasileiro de Informática na Educação (CBIE 2016)

Logo no início da aventura o programador é auxiliado por um mestre da programação (figura 3). Esse mestre também foi sequestrado no passado, mas infelizmente não conseguiu escapar do calabouço, justamente por só saber programar e não saber como combater as forças do mal. Por ver o personagem principal do jogo vestido de ninja, ele acredita que o programador é realmente um ninja. Durante toda a aventura o mestre segue alertando, ensinando e dando palpites ao jogador. A figura do mestre programador é de fundamental importância, no sentido de guiar o programador ninja nessa fuga inédita.

\section{SKELTON}

Skelton (Figura 4) é o grande arquiteto desse plano nada ético. Skelton quer obrigar algum programador a hackear o MonsterBook (rede social famosa entre os monstros das profundezas da Terra) de sua namorada, por isso ele vem sequestrando vários programadores ao passar dos anos. Skelton, quase não aparece durante o jogo, mas é muito mencionado durante a aventura, a interação com ele se dá na última cena do jogo.

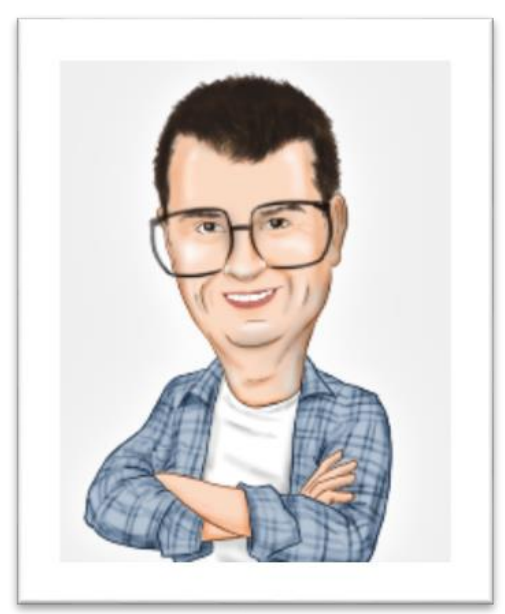

Figura 3.0 mestre programador

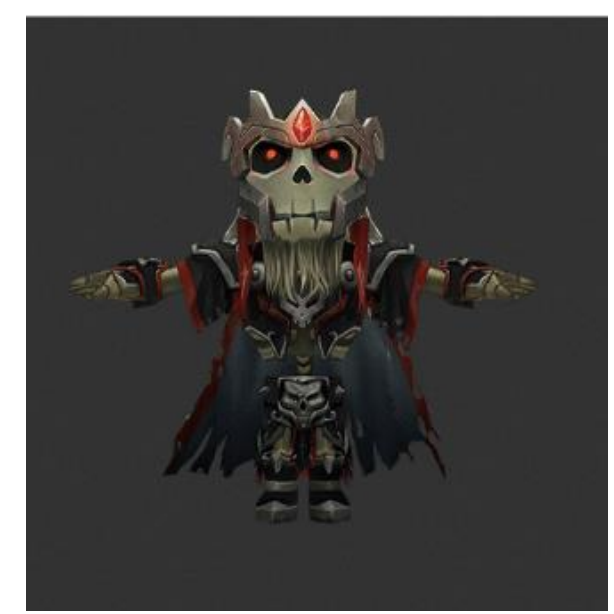

Figura 4. Skelton, o grande vilão

Além desses 3 personagens principais, existem muitos inimigos a serem derrotados durante as 16 fases do jogo, entre eles estão "debug turtle", a planta "carnivourus recursivus" e as "mumias dos laços de repetição".

\subsection{Sequenciamento das Fases}

O jogo Ninja Prog possui 16 níveis/fases que abordam vários conceitos da matemática básica e pensamento lógico. Por se tratar de um jogo, ele precisa ser divertido e ter o poder de engajar o usuário, para que o mesmo exercite seus conhecimentos enquanto se diverte jogando. No quadro 1, é apresentado uma visão geral de quais conceitos são abordados em cada fase. 
V Congresso Brasileiro de Informática na Educação (CBIE 2016)

Anais dos Workshops do V Congresso Brasileiro de Informática na Educação (CBIE 2016)

\begin{tabular}{|c|c|c|c|c|c|c|c|c|}
\hline Fase & 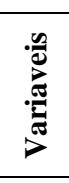 & 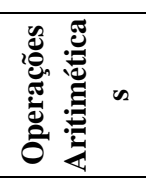 & 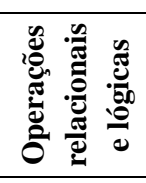 & 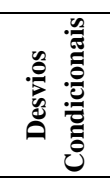 & 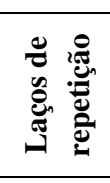 & 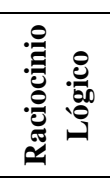 & 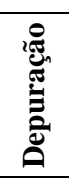 & 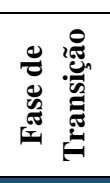 \\
\hline \multicolumn{9}{|l|}{ Fase 1} \\
\hline \multicolumn{9}{|l|}{ Fase 2} \\
\hline \multicolumn{9}{|l|}{ Fase 3} \\
\hline \multicolumn{9}{|l|}{ Fase 4} \\
\hline \multicolumn{9}{|l|}{ Fase 5} \\
\hline \multicolumn{9}{|l|}{ Fase 6} \\
\hline \multicolumn{9}{|l|}{\begin{tabular}{|l|} 
Fase 7 \\
\end{tabular}} \\
\hline \multicolumn{9}{|l|}{ Fase 8} \\
\hline \multicolumn{9}{|l|}{ Fase 9} \\
\hline \multicolumn{9}{|l|}{ Fase 10} \\
\hline \multicolumn{9}{|l|}{ Fase 11} \\
\hline \multicolumn{9}{|c|}{ Fase 12} \\
\hline \multicolumn{9}{|c|}{ Fase 13} \\
\hline \multicolumn{9}{|c|}{ Fase 14} \\
\hline \multicolumn{9}{|c|}{ Fase 15} \\
\hline Fase 16 & & & & & & & & \\
\hline
\end{tabular}

Quadro1. Visão geral de quais conceitos são abordados em cada fase.

Após as apresentações iniciais, o jogador é direcionado ao menu do jogo (figura 5). No menu é possível começar uma aventura nova ou continuar a partir do último progresso salvo. Os progressos são salvos automaticamente ao avançar entre os níveis.

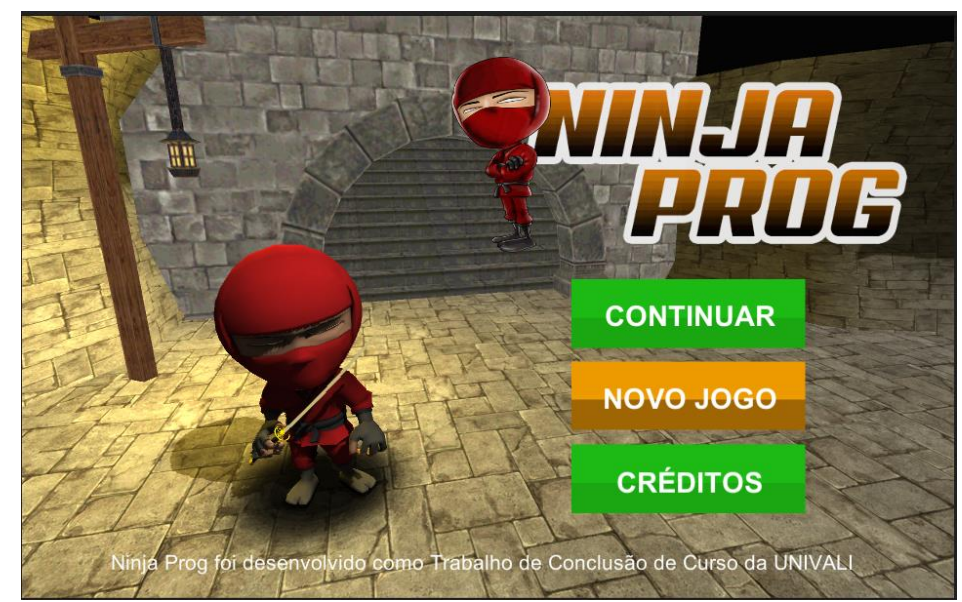

Figura 5. Menu inicial do jogo 
V Congresso Brasileiro de Informática na Educação (CBIE 2016)

Anais dos Workshops do V Congresso Brasileiro de Informática na Educação (CBIE 2016)

Durante a aventura o usuário precisa resolver problemas relacionados a pensamentos lógicos, operações aritméticas, manipulação de valores entre variáveis enquanto se diverte em um jogo de ação e aventura (figura 6).

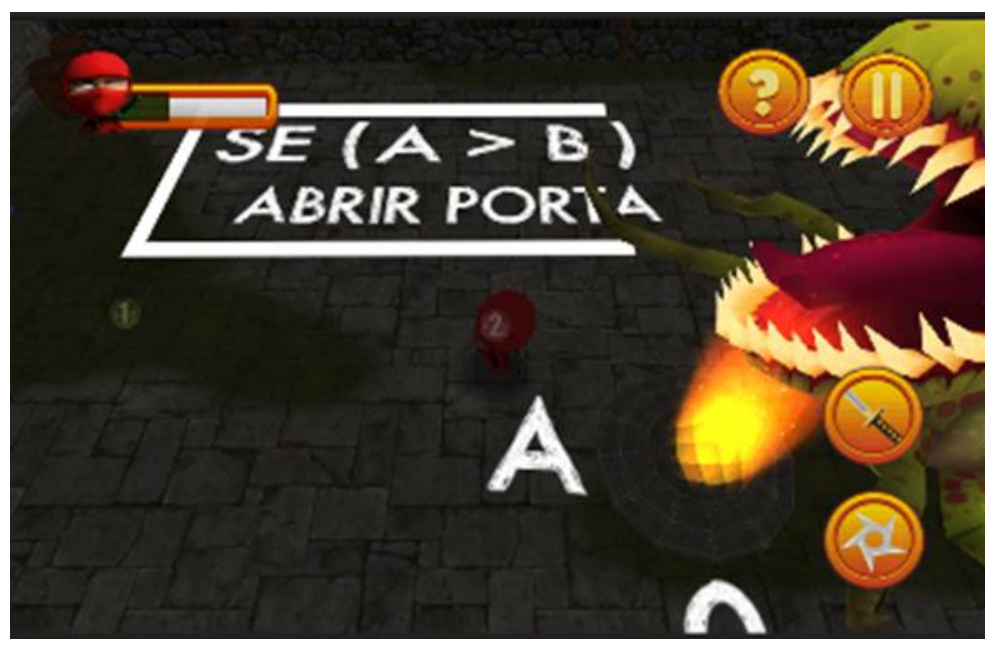

Figura 6. Figura ilustrativa de um dos níveis do jogo

\section{Considerações finais}

O jogo Ninja prog foi planejado e desenvolvido com o intuito de ajudar estudantes ou não, a exercitarem seu pensamento lógico enquanto se divertem um pouco jogando ao celular por exemplo. Ele é um jogo de aventura no qual o personagem principal precisa pensar um pouco para avançar nas fases e não somente dar espadadas em tudo o que aparece pela frente. É esperado que ajude os jogadores a compreenderem como funciona um desvio condicional e um laço de repetição por exemplo. O jogo tenta trabalhar com conceitos educacionais, sem a forte aparência de um típico jogo educacional.

Os próximos passos a serem dados no projeto são:

- A implementação de uma loja virtual com o intuito de tornar o jogo ainda mais atrativo e divertido. Nessa loja vai ser possivel adquirir vestimentas e armas novas além de conseguir obter dicas para resolução dos problemas.

- Disponibilizar o jogo para novas plataformas, como desktop e IOS.

- Tradução do jogo para novas linguas como o inglês e o espanhol. 
V Congresso Brasileiro de Informática na Educação (CBIE 2016)

Anais dos Workshops do V Congresso Brasileiro de Informática na Educação (CBIE 2016)

\section{References}

JENKINS, T., (2002). On the difficulty of learning to program. Proceedings of the 3rd Annual LTSN_ICS Conference, Loughborough University, United Kingdom, 53-58.

KIRRIEMUIR, John; MCFARLANE, Angela. Literature Review in Games and Learning. Bristol: Futurelab, 2004. 39 p. Disponível em: hal.archives-ouvertes.fr/hal00190453/document. Acesso em 27 abr 2015.

LAHTINEN, E., ALA-MUTKA, K. \& JARVINEN (2005). A studdy of difficulties of novice programmers. Proceedings of the 10th Annual SIGCSE Conference on Innovation and Technology in Computer Science Education, Monte de Caparica, Portugal, 6468.

MOURSUND, David. Math Maturity: Some Examples Helping to Describe Math Maturity. $2007 . \quad$ Disponível $\quad<$ em: pedia.org/Math_Maturity\#Some_Examples_Helping_to_Describe_Math_Maturity>. Acesso em: 15 abr. 2015. 